\title{
STUDY ON FOOD SAFETY AND FOOD HYGIENE OF FAST FOOD OUTLETS IN COLOMBO DISTRICT
}




\section{STUDY ON FOOD SAFETY AND FOOD HYGIENE OF FAST FOOD OUTLETS IN COLOMBO DISTRICT}

BY

H.K.P. THARANGI HERATH

Thesis submitted to the University of Sri Jayewardenepura as the partial requirement for the award of Master's of Sciences in Food Science \& Technology on 2015 


\section{DECLERATION}

The work described in this thesis was carried out by me under the supervision

of Dr. ( Ms. ) Indira Wickramasinghe, Department of Food Science and Technology, Faculty of Applied Science, University of Sri Jayewardenapura, and a report on this has not been submitted in whole or in part to any other University or any other institution for another Degree.

$08-12-2015$

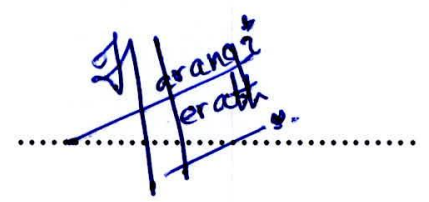

Date

Signature 


\section{DECLARATION}

I, Dr ( Ms. ) Indira Wickramasinghe certify that above statement made by the candidate is true $\&$ that this thesis is suitable for submission to the purpose of evaluation.

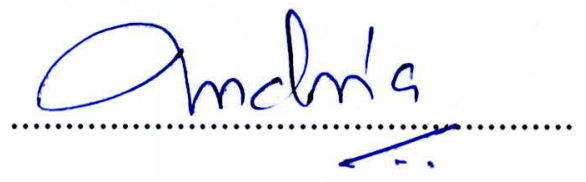

Dr. (Ms.) Indira Wickramasinghe,

Senior Lecturer,

Faculty of Applied Science,

Department of Food Science \& Technology,

University of Sri Jayewardenapura,

Gangodawila, Nugegoda,

Sri Lanka. 
MY LOVING PARNENTS, BROTHER \& DEAR TEACHERS 


\section{CONTENTS}

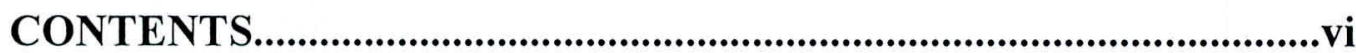

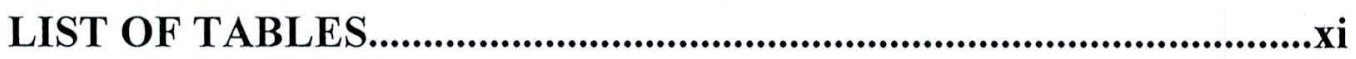

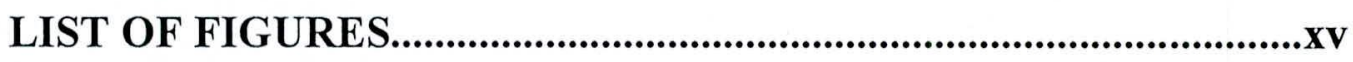

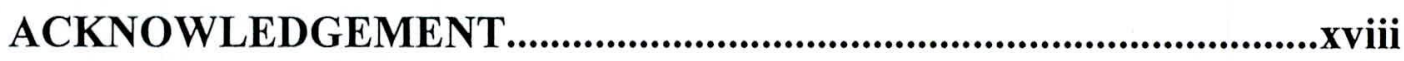

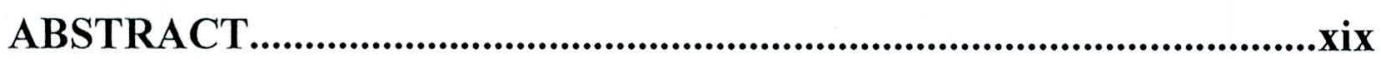

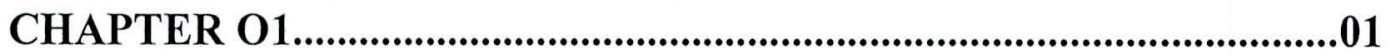

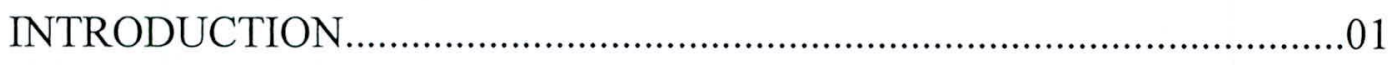

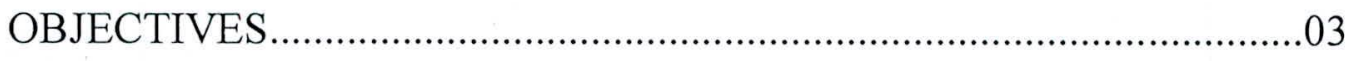

CHAPTER 02 ................................................................................................04

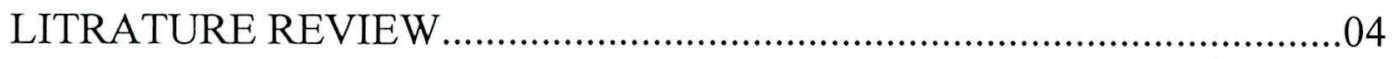

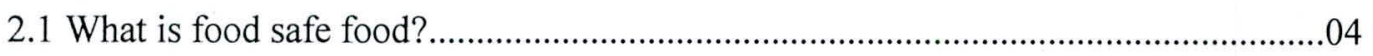

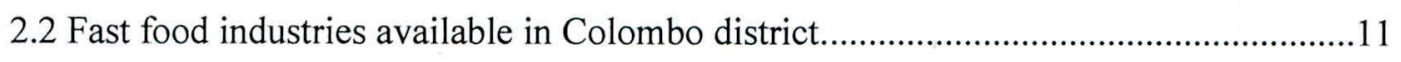


2.6.1.1. Core information. .19

2.6.1.2. Why? .20

2.6.1.3. Consideration \& Suggestions for the trainer. .21

2.6.1.4. How to keep yourself clean, Hand washing.

2.6.1.5. Consideration and suggestions for trainees.

2.6.1.6. How to clean plates \& utensils.

2.6.1.7. How to protect cooking areas from pests .22

2.6.2. Separate raw and cooked.

2.6.2.2. Why? . .23

2.6.2.3. Consideration \& Suggestions for the trainer.

2.6.2.4. How to keep raw and prepared food separately .24 
2.6.3.1. Core information

2.6.3.3. Consideration \& Suggestions for the trainer.

2.6.3.4. Cooking safely in the microwave oven .25

2.6.3.5. How to cook food thoroughly.....

2.6.4.1. Core information .26

2.6.4.2. Why? .26

2.6.4.3. Consideration \& Suggestions for the trainer. .26

2.6.4.4. What are the safe temperatures of the foods. .27

2.6.4.5. How to keep foods at safe temperatures .27

2.6.5. Use of safe waters and raw materials. .28

2.6.5.1. Core information .28

2.6.5.2. Why? .28

2.6.5.3. Consideration \& Suggestions for the trainer. .29 viii 
2.6.5.4. What is safe food .29

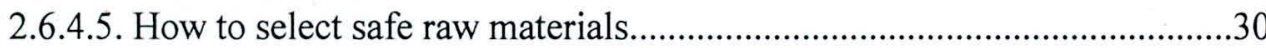

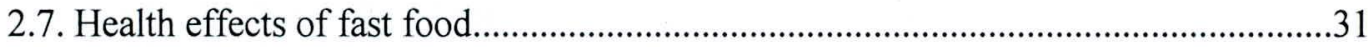

2.7.1. Some negative health effects of fast food...................................................31

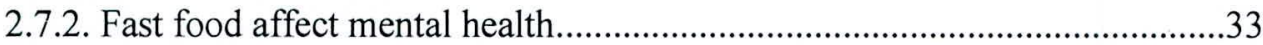

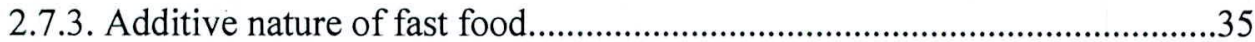

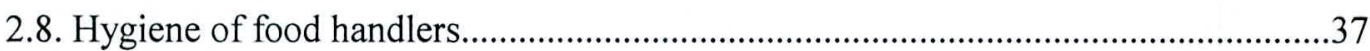

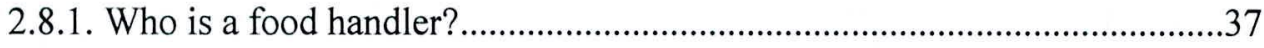

2.8.2. What must a food handler do if she or he sick?.........................................38

2.8.2.1. If a food handler has a food borne illness......................................38

2.8.2.2. If a food handler has skin injuries or sores or is otherwise unwell..39

2.8.2.3. If a food handler knows or suspect he or she might have contaminated some food 40

2.8.3. What about personal hygiene? 40

CHAPTER 03. 
CHAPTER 04

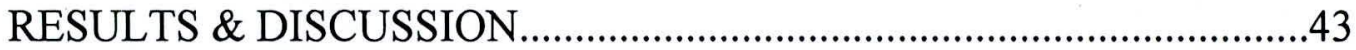

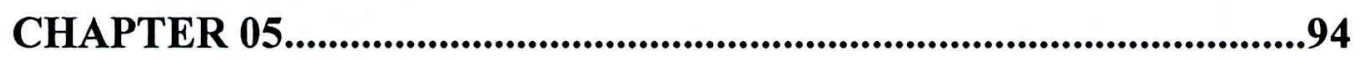

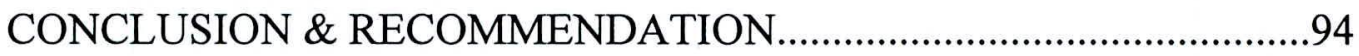

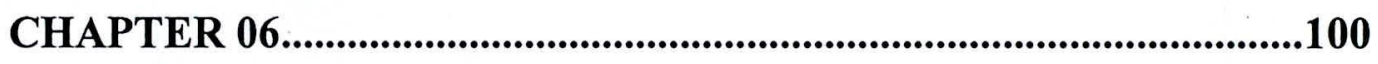

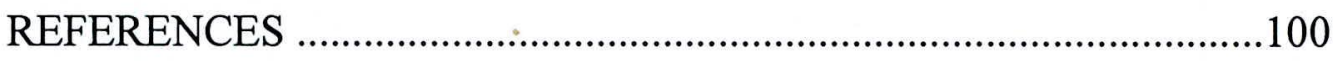

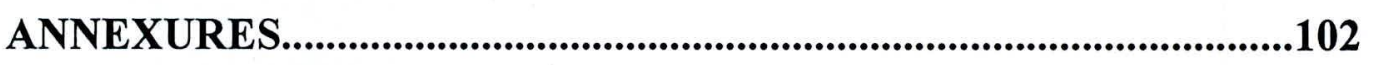

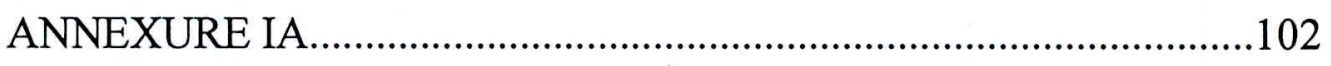

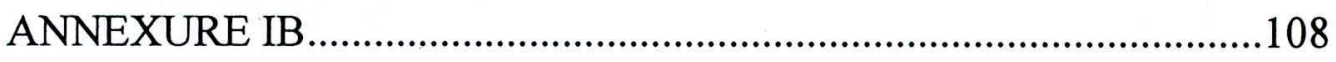




\section{LIST OF TABLES}

Table 4.1 Hand washing methods in the company.........................................................44

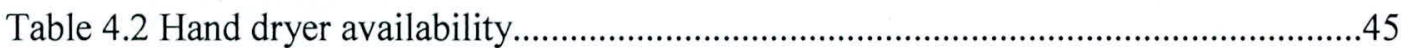

Table 4.3 Places where the hand washers are available.................................................46

Table 4.4 Washing hands before cooking serving \& after visiting to toilet.......................47

Table 4.5 Satisfaction about the hand washing procedure............................................48

Table 4.6 Why to follow up hand washing procedure?...................................................49

Table 4.7 Have two different water supply system to cooking \& washing.........................50

Table 4.8 Enough water supply for both cooking \& washing purposes.............................51

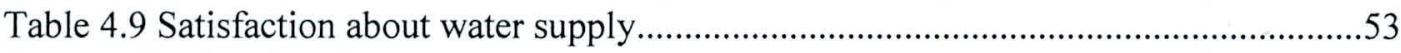

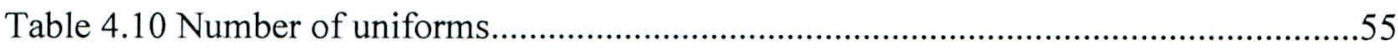

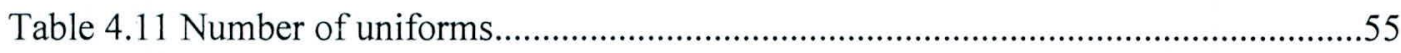

Table 4.12 Standard washing method is given..........................................................57

Table 4.13 Satisfaction of durability \& comfortability of uniforms.......................................57

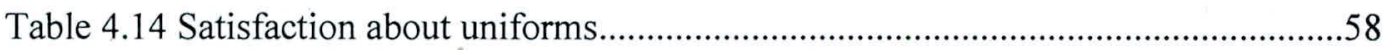

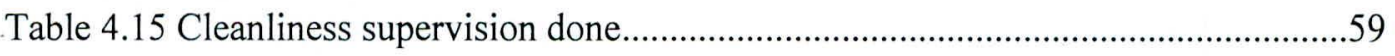


Table 4.16 Enough storage facilities.

Table 4.17 Separate storage facilities for raw \& cooked food.

Table 4.18 Enough storage facilities for crockery utensils.

Table 4.19 Satisfaction about the storage facilities .66

Table 4.20 Crockery/cutlery cleaning procedures. .66

Table 4.21 Satisfaction of crockery/cutlery cleaning. .67

Table 4.22 type of waters use to cleaning of crockery/cutlery. . .69

Table 4.23 Number of garbage bins in the kitchen.

Table 4.24 Garbage bins have foot valves .70

Table 4.25 Satisfaction of garbage disposal facilities. .70

Table 4.26 Garbage bin cleaning method. .70

Table 4.27 Usage of gloves. 72

Table 4.28 Usage of masks. . .73

Table 4.29 Satisfaction of gloves \& mask usage... . .73

Table 4.30 Gloves usage rules. .74

Table 4.31 Food discarding procedures. .75

Table 4.32 Satisfaction of food discarding procedures. . .77 
Table 4.33 Enough training is given

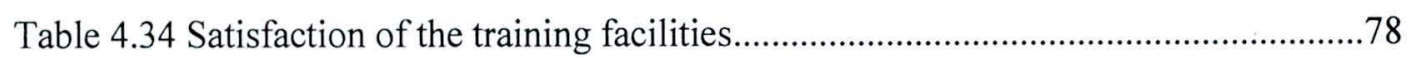

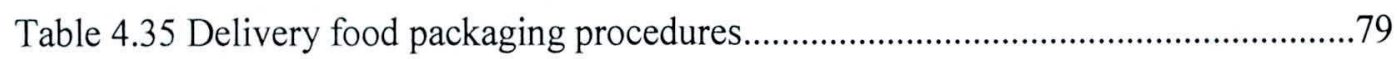

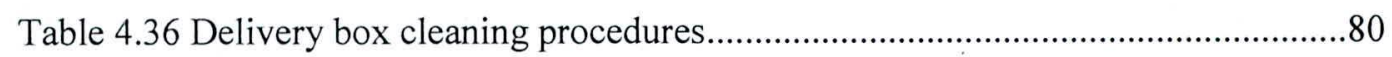

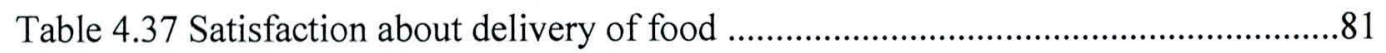

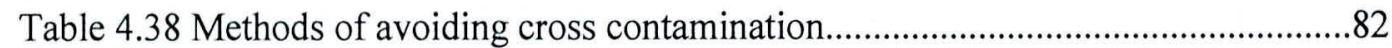

Table 4.39 Satisfaction of cross contamination prevention...........................................83

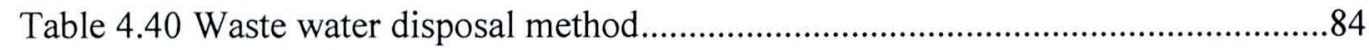

Table 4.41 Satisfaction of waste water \& waste disposal method........................................86

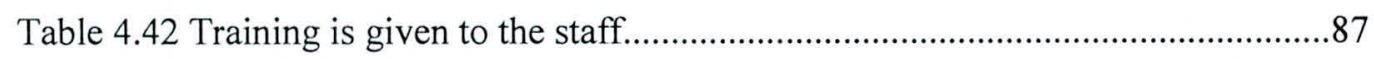

Table 4.43 Approved suppliers for raw materials........................................................8

Table 4.44 Satisfaction of the raw material suppliers.......................................................8

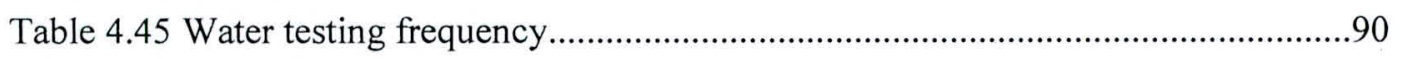

Table 4.46 Recommended place for medical testing..................................................90

Table 4.47 Medical certificate should indicate whether worker is fit to work .................90

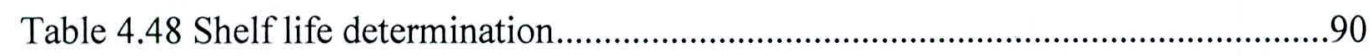

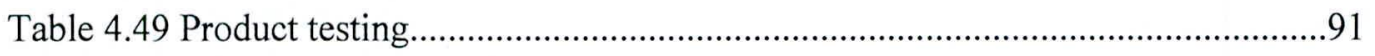


Table 4.50 Minimum qualification of the staff...............................................................92 


\section{LIST OF FIGURES}

Table 4.1 Hand washing methods in the company..........................................................44

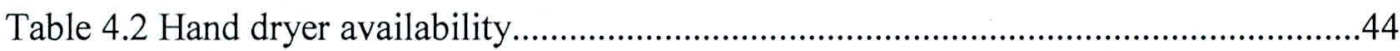

Table 4.3 Places where the hand washers are available......................................................45

Table 4.4 Washing hands before cooking serving \& after visiting to toilet.........................45

Table 4.5 Satisfaction about the hand washing procedure...............................................46

Table 4.6 Have two different water supply system to cooking \& washing.........................46

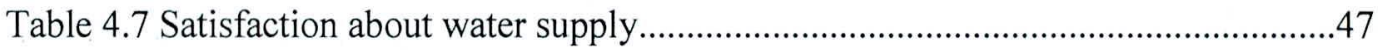

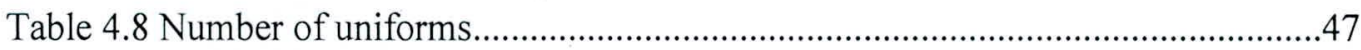

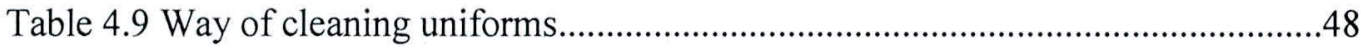

Table 4.10 Satisfaction of durability \& comfortability of uniforms................................49

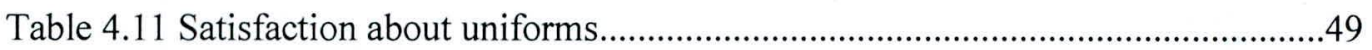

Table 4.12 Enough storage facilities..........................................................................50

Table 4.13 Enough storage facilities for crockery utensils...............................................50

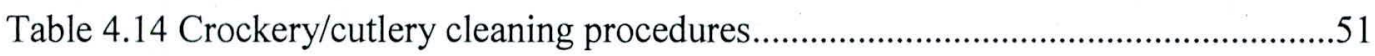

Table 4.15 type of waters use to cleaning of crockery/cutlery ......................................52 
Table 4.16 Number of garbage bins in the kitchen

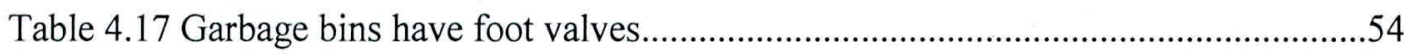

Table 4.18 Satisfaction of garbage disposal facilities......................................................5

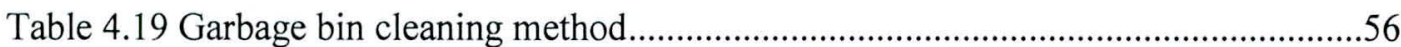

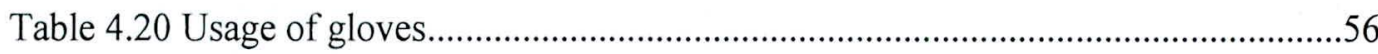

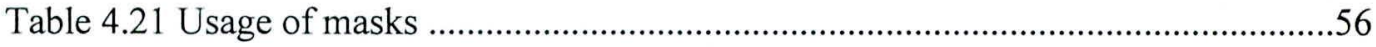

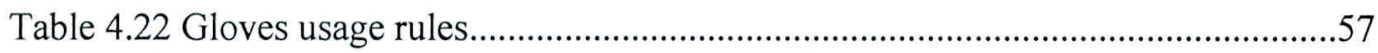

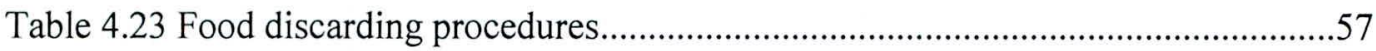

Table 4.24 Delivery food packaging procedures............................................................58

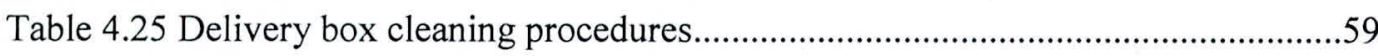

Table 4.26 Methods of avoiding cross contamination........................................................59

Table 4.27 Waste water disposal method...................................................................60

Table 4.28 Satisfaction of waste water $\&$ waste disposal method...................................62

Table 4.29 Approved suppliers for raw materials......................................................64

Table 4.30 Water testing frequency................................................................................6

Table 4.31 Recommended place for medical testing.........................................................68

Table 4.32 Medical certificate should indicate whether worker is fit to work...................70 xvi 
Table 4.33 Table 4.48 Shelf life determination.

Table 4.34 Product testing.. . .73

$\div$ 


\section{ACKNOWLEDGMENT}

First and foremost I respectively express my deepest gratitude to my supervisor, Dr ( Ms. ) Indira Wickramasinghe, Senior Lecturer of Food Science and Technology, Faculty of Applied Sciences, University of Sri Jayewardenepura for her inspiring guidance, opinions and support to the preparation of this thesis. And I also would like to express my sincere gratitude to Dr. M.A Jagath Wansapala, Course coordinator, M.Sc. Food Science and Technology, Faculty of Applied Sciences, University of Sri Jayewardenepura who was always willing to discuss the problems that I encountered during my research project. I also like to pay my gratitude to all other academic and non-academic staff for the support and encouragement towards me. I would like to pay my gratitude to Ms. Amani who help me to build up the questionnaire.

I would like to express my kind gratitude to Managers and Employees who gave their kind support to do my survey in excellent.

I would like to pay my gratitude to the consultancy panel of the Statistics and Computer Science Department, Faculty of Applied Sciences, University of Sri Jayewardenepura who helped me to do the statistical analysis in this report.

Last but not least, I would like to extend my heartfelt appreciation for the corporation given by my colleagues and my heartiest thank overflow on my dear parents, brother, Mr. Binal Bandara and his mother who helped me to collect all the data for my survey in effective manner. And also to my friends who given me courage by a single word in erect this report truth. 


\title{
STUDY ON FOOD SAFETY AND FOOD HYGIENE OF FAST FOOD OUTLETS IN COLOMBO DISTRICT
}

\author{
By
}

\author{
Herath H. K. P. T
}

\begin{abstract}
Food safety is a global concern. Food safety is related to the presence of food-borne hazards in the food at the point of consumption. Therefore food safety hazards should be controlled through out the food supply chain effectively to deliver safe product to the consumer ( End user for its intended use ). And also, there is a growing demand of consumers for healthy and safe food products. It is a big challenge for people who have been involved in food related business industry to supply for the demand of safe food products. As fast food is growing very fast in the Sri Lankan context, it is very useful to know about the knowledge of adequacy about food safety and food hygiene of the employees whom work in the fast food outlets.
\end{abstract}

A questionnaire based survey was carried out among 30 fast food out lets, for 90 employees and 30 managers to find out whether they have adequate knowledge about food safety and hygiene and whether managers are willing to facilitate to maintain the food safety and hygiene in the outlets. 